\title{
ICT Strategy in an ICT User Perspective: Exploring Alignment between ICT Users and Managers
}

\author{
Harald Fardal \\ Bodø Graduate School of Business, Bodø, Norway
}

haf@hive.no

\begin{abstract}
This study adds to the body of knowledge in research of ICTs in organizations by exploring the relevance of alignment between ICT users and managers responsible for the ICT strategy and ICT project processes. Alignment research is usually conducted at an organizational analytical level, but this study explores alignment between individuals by addressing ICT managers and ICT users, considering both the organizational and individual perspectives. Data was collected by interviewing ICT users and the $\mathrm{CIO}$ in a Norwegian entrepreneur corporation. Using a grounded theory analytical approach, the findings provide support for an emerging User Management Alignment Model (UMAM) where the outcome is better ICT strategy and project processes.
\end{abstract}

Keywords: ICT strategy, ICT projects, alignment, user participation, user satisfaction, user initiatives

\section{Introduction}

Although researchers have given a lot of attention to information and communication technology (ICT) strategy (Henderson \& Venkatraman, 1993, 1999; Reich \& Benbasat, 2000), they have mainly focused on the managerial perspectives, which leaves unanswered questions concerning 1) the ICT strategy's consequence for the users, 2) users' ability to do ICT strategic considerations, 3) user involvement in ICT strategy processes and 4) users' actions influence on ICT strategy quality. This study adds to the body of knowledge by exploring the relevance of alignment between ICT users and managers responsible for the ICT strategy and project processes. Well formulated ICT strategies make it possible to identify and define the right ICT projects, however defining the right projects do not imply that the projects will be successful. Studies suggests there are several reasons for ICT project failure (Aladwani, 2002; Oz \& Sosik, 2000). Research that contributes to identify factors to improve ICT strategy and project processes can have normative as well as economic implications for organizations. This study aims to make a contribution to this research domain, and hence to have normative as well as academic implications.

Alignment research is usually conducted at an organizational analytical level, but this study ex-

Material published as part of this publication, either on-line or in print, is copyrighted by the Informing Science Institute. Permission to make digital or paper copy of part or all of these works for personal or classroom use is granted without fee provided that the copies are not made or distributed for profit or commercial advantage AND that copies 1) bear this notice in full and 2) give the full citation on the first page. It is permissible to abstract these works so long as credit is given. To copy in all other cases or to republish or to post on a server or to redistribute to lists requires specific permission and payment of a fee. Contact Publisher@InformingScience.org to request redistribution permission. plores alignment between individuals and including both organizational and individual perspectives. Many modern organizations consist of employees with high competence and expertise within their area, and exploiting this expertise should be of interest for most organizations. Although ICT strategy literature often addresses the issue of user participation, especially in defining system specifications, the role of users' in ICT 
strategy processes remains ambiguous. It is unlikely that this issue holds one solution; however, it is likely that some general principles may be developed. Organizations striving to improve the ICT strategy creation and implementation processes will find this research relevant.

Prior alignment research holds the notion that a firm's ICT strategy should be aligned with its other strategies. Henderson and Venkatraman (1993) developed the Strategic Alignment Model (SAM), which describes different approaches to alignment between business and ICT strategies. Broadbent and Weill (1993) investigated organizational change in the banking industry to improve alignment between information and firm strategies, and Grover and Malhotra (1999) link information systems to manufacturing operations. Sabherwal and Chan (2001) study the impact alignment between business and IT strategy has on firm performance. Although these and other studies have contributed to increased understanding of the various components of alignment between ICT and business strategies, they have had a macro focus; alignment in regards to structure of the ICT organization, information systems, ICT architecture or overall ICT strategy. As far as this author knows, there are few studies that have examined alignment between individuals or groups of individuals in organizational issues. Cross-level analysis is rarely conducted between the organizational and individual level in ICT research. However, we must investigate and develop knowledge about how organizational and individual factors interrelate and influence each other to better understand the processes concerning ICTs in organizations.

Reich and Benbasat (2000) investigated the social dimension of strategic alignment, and their results indicate that the individual level should be included when studying ICT strategic phenomena. Including the ICT user perspective in this research domain will strengthen our knowledge on the mechanisms that gives better use if ICTs as well as identifying factors leading to alignment between ICT users and ICT managers. Especially interesting is the linkage between ICT strategy, ICT projects and ICT use, as it is a prerequisite that the technologies and information systems organizations try to implement are used in a proper way.

Using an inductive approach, data was collected by interviewing various individuals in a 6000 employee entrepreneur corporation in Scandinavia. A qualitative analysis is conducted - using a Grounded Theory approach - to theorize the findings. Besides developing theory based on the findings and thereby extending the nomological network within this research domain, the study aims to have normative contextual contributions for practitioners.

The rest of the paper is organized as follows: First, a presentation of the theoretical background presentation including research questions and a discussion of prior research relevant to my research questions. Next is the methodology presentation, followed by the data analysis and results discussion. The paper ends with concluding remarks and directions for future research.

\section{Theoretical Background and Research Questions}

The Grounded Theory approach indicates little or no literature review prior to data collection and analysis (Glaser \& Strauss, 1967). However, some literature review will strengthen the analyst's ability to explore patterns in data (Strauss \& Corbin, 1994). Hence a brief literature review was done before I entered the field and it served as a sensitizing device (van den Hoonaard, 1997) during the subsequent data analysis. The rest of the literature review was, in accordance with grounded theory, conducted parallel to the data analysis.

ICT strategy is a managerial responsibility and Sambamurthy and Zmud (1992) view ICT management as a problem of aligning the relationship between the ICT infrastructure and business domain, in order to take advantage of ICT capabilities and opportunities. Research literature seems to hold two approaches to ICT strategy. One focuses on planning procedures, structure and examining the strategies, and the other on the actors involved, their communication and under- 
standing of each others' domains (Reich \& Benbasat, 2000). In this paper I focus on the latter approach.

Strategy development consists of three elements: 1) strategic analysis 2) strategic decisions, and 3) strategy implementation (Barney, 2002), and achieving strategic success relies on well driven processes. Any strategy development project must be rooted in the organization's top management and the processes should preferably be managed by a carefully selected project group (Gottschalk, 2002). The term strategy is in this paper understood as the set of processes that leads to the three elements strategic development consists of.

Researchers consider alignment between business objectives and ICT as a key factor for enhancing organizational outcome, with Henderson and Venkatraman's $(1993 ; 1999)$ strategic alignment model being the reference model for most research. They found that alignment of business strategy and ICT strategy improves firms' performance. However, this model has been criticized for its narrow focus on the technology itself, and the exclusion of social factors (Ba, Stallaert, \& Whinston, 2001; Reich \& Benbasat, 2000). Factors like organizational artifacts and culture, social relations and individual traits are not a part of Henderson and Venkatraman's model. Ba et al. argue that both alignment and ICT development research lacks focus on user incentives and that users' objectives often differ from organizational objectives. They introduce a new dimension to alignment between business objectives and ICT, which they refer to as incentive alignment. Developing incentives on how to use, when to use and who should use must be a part of the ICT strategic processes and systems development projects (usually initiated through an ICT strategy). The incentive alignment model consists of four elements:

- Incentives influencing user behavior and the user's interaction with the system

- Deterrence of use for personal gain

- Use consistent with organizational goal

- Robustness against information misrepresentation

The incentive alignment model represents a new direction in alignment research; however I interpret it as a top-down model, for management to control user behavior. Reich and Benbasat (2000), on the other hand, studied the social dimension of ICT strategy development. Communication and a shared knowledge domain proved to be important for strategic alignment. Both for short term and long term alignment their results indicate that the level of official and unofficial communication combined with the degree of shared domain knowledge influence the degree of alignment between business objectives and ICT.

Peak et al. (2005) did a case study were they investigated IT alignment planning in an American corporation. They describe IT alignment planning as “... IT Alignment Planning takes a strategic view across the corporation. It identifies or discovers and creates new IT strategies, identifies and creates new IT resources, provides input into strategic and tactical planning processes, and factors in the effects of competition with the primary objective of improving information quality for IT clients" (Peak et al., 2005 p. 636). Although they also have a management focus, their findings indicate some benefits in how ICT users perceive the technology. They report that IT Alignment Planning:

- Aligns corporate and client business goals

- Creates a decision and capital budgeting

- Dovetails with the corporate strategic

- Develops IT vision integrated with business 
- Facilitates executive-level understanding

- Helps improve operational IT support of

- Brings IT and client closer together

The referenced studies above have one commonality - they all have a managerial perspective. Sure they discuss the importance of effects on ICT use and so forth, but either their respondents are managers, they hold a top-down view of organizational processes, or both.

It is understandable that ICT strategy research usually has a management perspective, as managers have the strategic responsibility. However, in studies of ICT project success the rarity of the user perspective is more surprising. Oz and Sosik's (2000) study of why information system projects are abandoned provides an example of such. They gathered data from ICT management in organizations to explain the phenomenon. Their found five major reasons of why projects are abandoned, including project objectives are poorly communicated, lack of corporate leadership, insufficient skill, poor project management and time/budget deviations. The user perspective is not included. Aladwani's (2002) study of an information system project performance model focus on project management and leaders were chosen as the study's respondents.

Although this is not a study of ICT use, it has a strong focus on the user perspective. A brief overview of previous ICT use literature is hence given to present topics researchers focusing on the user have studied. ICT use refers to the actual use of ICTs in the workplace (Davis \& Wiedenbeck, 2001), and research on ICT use has been comprehensive and varied (i.e. Adams, Nelson, \& Todd, 1992; Agarwal \& Karahanna, 2000; Agarwal \& Prasad, 1998; Barki \& Hartwick, 1989, 1994; Brod, 1982; Liaw, 2002; Sørnes, 2004), and user involvement, user satisfaction and users' choice of media for communication are examples of topics. However, organizational aspects are not included in the analysis, and thus we have little knowledge of how organizational factors influence user behavior; in other words, the degree to which these factors influence how users perceive the technology and ultimately how they use it.

While research on ICT strategy, ICT projects and ICT users has produced important knowledge for both practitioners and academics, the aim of this study is to explore how the processes involved in ICT strategy and ICT projects can be aligned with ICT users' perspectives.

Initiating research in this area is important for three reasons: First, ICT research is very dynamic with new technologies emerging at a rigorous pace, and finding and identifying some technology independent factors is important in order to understand and act upon this. Second, organizations must be able to formulate ICT strategies that reflect their needs, are economically realistic and are in alignment with their business strategies, as research shows that many organizations struggle to implement their ICT strategy (Gottschalk, 2002). Hence, processes concerning both development and implementation of ICT strategy need to be improved. Third, ICT use is important for organizational performance, and hence we still need to add to the knowledge of how to improve use and to which degree users can contribute in ICT strategy and project processes

This paper introduces another dimension to alignment research, focusing on alignment between users and managers. The dimension includes the belief that alignment between users and managers is important for strategic alignment, and it has both a bottom-up and top-down focus. The following research questions provide the basis for this study:

- To which degree is there alignment between users' and managements' view of important ICTs for the organization?

- Why is there alignment or not between users' and managements' view of important ICTs for the organization? 


\section{Methodology}

Grounded Theory (GT) is chosen as the methodological approach in this study, primarily because it facilitates the generation of descriptions and explanations to complex organizational processes. Within ICT research GT has become more common the last 10-15 years (e.g. Carlson \& Davis, 1998; Levina \& Ross, 2003; Orlikowski, 1993). However, GT has been widely applied in other business and organizational studies for the last 30 years (Locke, 2001). GT has, according to Locke, proven to be particularly useful when examining organizational topics like decision making, socialization and change. In organizational studies one often focuses on individual and group behavior and this captures the initial locus and interactionist tradition of GT (Glaser, 1992; Locke, 2001).This, combined with its structured and analytical properties, is probably an important explanation of its popularity in business and organizational research.

This project enters a relatively unstudied area. Consequently, there is insufficient existing theory, and hence the suggestion that when studying a topic that is emergent or ill-defined, it should be explored in the field using a qualitative methodology (Patton, 1990; Steinfield \& Fulk, 1990). It is evident that the GT approach is well suited for organizational studies, both on the organizational and individual level of analysis. In this project both analysis on both levels will be conducted and the explorative approach of GT will provide the cross comparability across the two levels of analysis. Furthermore, GT allows for "the generation of theories of process, sequence, and change pertaining to organizations, positions, and social interaction" (Glaser \& Strauss, 1967). The ICT strategy processes are indeed very dynamic and can have considerable impact on organizational performance (Croteau \& Bergeron, 2001; Gottschalk, 2002; Henderson \& Venkatraman, 1993, 1999).

Strauss and Corbin (1990) argue that a qualitative methodology enables the researcher to convey intricate details about a phenomena - details that will be concealed with quantitative methods. GT is well suited to capture variation as its flexibility allows researchers to modify their analysis in an iterative data collection process (Locke, 2001). Meeting people in their workplace environment is to me a prerequisite for understanding how they perceive their role in an ICT strategic process, how they perceive their organization's ICT strategic processes and how they perceive their own use of ICTs.

\section{Research Site and Participants}

A 6000 employee sized Norwegian entrepreneur corporation was targeted as the case in this study. The company is organized as a corporation with several divisions operating in the whole of Scandinavia. It was selected as case for two reasons. First, the organization is highly decentralized and characterized by high degrees of personal and divisional freedom that can gives some challenges in ICT strategic development. Mintzberg and Mchugh (1985) use the term adhocracy when they describe The National Film Board of Canada, and the corporation in this study fits an "adhocracy light" description. It provides managers the challenge of keeping an overview over the activities in the organization at all times. Second, as the core of business is building houses, roads, tunnels and so forth, exploring to which degree the organization prioritize ICT could be relevant to the way strategic processes are conducted and how ICT is used.

According to Strauss and Corbin (1990) a theoretical sampling procedure should be used in conjunction with GT (Resnik Mellion \& Moran Tovin, 2002). As I am investigating timely processes the targeted interviewees in this project have been employed in the organization for at least three years, and depend on ICT-systems in their everyday work. People need to be a part of an organization for some time to experience the ICT strategic processes and thus enable one to evaluate them. It was also vital that the interviewees had some experience in using one or more strategically important ICT-system in the organization, because it is likely that strategic considerations 
have been done in connection with these systems. However, it is irrelevant at which level in the organization data is collected. I consider data from clerks to be just as valuable as data from managers or leaders in this context. In addition I will have to interview at least one person in the respective organizations who is accountable for the ICT strategy processes. Data from this interview will produce the ICT management perspective of alignment between ICT users and ICT managers.

The sampling procedure is a combination of narrow and wide sampling (Cutcliffe, 2000). A narrow sample consists of participants with a lot of experience within the area of interest, and supporters of it argue that one cannot comment on the studied processes if one does not share the same experiences (Resnik Mellion \& Moran Tovin, 2002). In a wide sample, on the other hand, the participants may have diverse background and experience. Supporters of wide sampling argue that it enables them to capture data with maximum variety (Resnik Mellion \& Moran Tovin, 2002). I use wide sampling because I allowed participants to come from different levels and divisions in the organization. However, allowing only participants with a certain experience who use a strategically important ICT system narrows the sample. This sampling process of selecting participants for their differences as well as their similarities fits with the sampling procedures suggested by Glaser and Strauss (1967) and Sørnes (2004).

\section{Data Collection}

Data was collected using semi-structured in-depth interviews. This method allows for adaption to each individual and to the context. Since I did not enter the field as a blank slate with respect to the area investigated, I was able to provide a manageable direction for the study (Strauss \& Corbin, 1990).

As a researcher I had to adapt to the degree of openness I met in the organization. Lofland and Lofland (1995) consider organizations to be non-public closed settings and this highlights two possible areas of caution. First of all, my behavior as a researcher could affect the reliability and quality of the respondents answers in the interviews. Therefore I had to adjust to, and understand, the communicational artifacts in the organization, and the questions needed to be formulated and addressed in an understandable manner. Second, non-openness amongst the subjects could affect the quality of the collected data. In the data collection process I paid attention to these factors, and hopefully avoided the possible negative outcomes.

An interview guide based on Spradley's (1979) "grand tour guide" was developed and data collection took place over a period of three months - from December 2006 to February 2007. Following Spradley's principles the interviewees were encouraged to tell the story of ICT strategy processes, using their experience as the reference. To further ensure richness the participants were first informed about the study and were given time to settle into the situation. The interview guide started with some general questions about the participants' use of ICTs and their competence in using them, in order to further familiarize them to the interview setting.

A total of fourteen interviews were conducted - thirteen with ICT users and one with the CIO. Each interview lasted between 40 and 75 minutes and was audio recorded. The transcription of the recordings resulted in more than 120 pages of single lined text. Following the principles of GT, literature was reviewed simultaneously to validate the theoretical perceptions (Glaser \& Strauss, 1967).

\section{Data Analysis}

All the interviews were imported into QSR Nvivo 7, a tool particularly suited to use in the coding processes of Grounded Theory. The first coding step identified a total of 586 categories; however coding iterations reduced this to five main categories. 


\section{Coding procedures}

The constant comparative analysis was used, as it enables the researcher to revise and modify its analysis as further data are gathered (Glaser, 1998; Glaser \& Strauss, 1967). The procedures consisted of two main steps: 1) incident identification and 2) categorization. It is important to emphasize that these analytical steps, including data collection, are iterative. During the first step incidents consisting of single sentences or short paragraphs were marked and labeled. The marking process of the ICT users interviews resulted in 538 different incidents, and in 48 incidents in the CIO interview. The categorization process reduced the incidents into five different categories, and these categories are the raw data used in this study.

The categories are:

- User participation

- User satisfaction

- User initiatives

- Management commitment

- Project process focus

Glaser and Strauss (1967) describe four different steps for constant comparative analysis . It is important to emphasize that these analytical steps, including data collection, are iterative. The steps are:

- comparing incidents applicable to each category,

- integrating categories and their properties,

- delimiting the theory, and

- writing the theory.

These steps have been followed closely. The first two steps, incident identification and categorization, Glaser (1998) refer to as open coding. For incident identification Glaser recommends a line-by-line coding process, where incidents from different cases are compared and labeled.

\section{Findings}

Achieving alignment between ICT management and ICT users requires a set of processes in the organization, and it may be achieved on both an ICT strategic and ICT project level. The following discusses these processes and the two different levels of alignment, and presents an emerging model of ICT users and ICT managers alignment - the User Management Alignment Model (UMAM).

Before presenting the different factors influencing the User Management Alignment (UMA) level, it is adequate to present the effects of UMA. This study provides support for two main effects of UMA. First, high UMA gives better ICT strategy and project processes, moreover, the users perceive the strategies and the projects to be sensible even if they are not involved in the processes and have little knowledge of them. Second, the respondents who experienced high UMA also reported above average competence in using the ICTs and that the ICTs they use are well suited to do what they are supposed to. The relationship between user competence and UMA may be reciprocal, as the data analysis did not produce any clear answers to the direction of it. 


\section{Strategic level UMA}

Many ICT strategies define some projects that will be implemented during a period of three to five years (Gottschalk, 2002). However, the slight adhocatric structure (Mintzberg \& Mchugh, 1985) of the studied organization reduces the corporate ICT strategy to an overview of focus areas, like having an overarching infrastructure and a common platform for e-mail. Although many of the projects are linked to the general points in this strategy, it is necessary to view UserManagement Alignment (UMA) on both a strategic and a project level. There is a common view in the organization that choosing the right projects are just as strategically important as the overall ICT strategy. This means that project level UMA must be considered equally important as strategic level UMA. According to the CIO, the ICT strategy was developed with participants from different areas of the organization and with strong user participation. However, none of the ICT users interviewed had any knowledge of what the strategy contains, and many did not even know of its existence; a fairly strong indication that the strategy has been poorly communicated in the organization. A mid-level manager explains: "We have an ICT strategy. I can say that, but I haven't read the strategy document as it's on top corporate level, but I do know that it came unreasonably late, and after tremendous pressure that I assume it reflects the feedback and the pressure that was, that the document is based on a bottom-up approach. That it isn't an illusion of a strategy, an academic exercise." A project worker expresses his knowledge of, or lack of knowledge of, the ICT strategy like this:" I haven't got a clue about the ICT strategy in our corporation. In spite of not knowing the content of the ICT strategy, most interviewees indirectly expressed much of the same strategic thoughts as the ICT strategy does. So without being aware of it, they experience that the ICT strategy to some extent is aligned with their beliefs of how the strategy should be, and hence strategic level UMA is also present to some extent.

The main reason to the conclusion that UMA exists to only some extent is that the ICT management has not communicated the strategy properly throughout the organization. While interviewees generally show an understanding of the ICT needs, they are more likely to accept new technology if they can prepare for it (Ba et al., 2001; Karahanna, Straub, \& Chervany, 1999; Venkatesh, 2000). A human relations manager states: "One mindsets people a little if one tells about what to expect within ICT, hence people can prepare themselves mentally of what to come." She calls for a communication of strategy needed to reach UMA to the full extent. Second, although the CIO says that user participation was strong in the strategy development process, it may anyhow have been too narrow as none of the interviewees knew anything about the process and the persons involved in it.

\section{Project level UMA}

The decentralized structure of the corporation conducting corporate wide ICT projects successfully is a challenge, and it requires a lot of time and resources. However, not all of the ICT projects are corporate wide; some limit themselves to a division or even to smaller units like a department or a project group. The different projects types appear to have some similar characteristics and the main difference are where the decisions are made. The similarities are:

- Often user initiated projects

- The project group involves users broadly

- Users are involved in the specification of requirements

- Time is not an issue, the process is 


\section{User initiated projects}

One of the most prominent characteristics of the organization in this study is the degree to which it relies on user initiatives in regards to ICT. It seems to be an accepted way of communicating ideas and needs both by managers and employees. A marketing clerk exemplifies it like this: "We have talked about CRM for many years, but it requires enthusiasts. It's not difficult to get support for doing things, but it's mostly done by enthusiasts. I think that's typical for our organization." The reliance on user initiatives contributes to UMA, because it enables everyone to communicate ideas that have a fair chance of being supported by management. However, far from everyone is an enthusiast and the challenge in this system is to ensure that the ideas are supported in the organization as a whole. Another issue also arises in a system like this; time. Although most of the interviewees appreciate a system where they can be the initiators of ICT projects, they mostly abstain from doing so as it allocates too much time in an already hectic work day. Both the CIO and the employees interviewed believe the organization need better routines for identifying ICT needs, as they now experience the process of identifying and choosing the right projects as slow. As a consequence the frustration amongst the groups that express the need for new ICTs may grow to unacceptable levels. However, the routines should be within the existing system of bottom-up communication of needs, as the following example from the dataset expresses: "One thing I miss is that we establish some arenas where we can exchange ideas, and of course find a way to separate the good ones from the bad ones."

Nevertheless the findings in this study provide support for user initiatives, together with other factors, as a premise for UMA.

\section{User participation and user satisfaction}

The project groups usually consist of at least one ICT project expert and people from different areas of the organization where the new ICT is to be implemented. Hunton and Beeler (1997) provide support for strong user participation in ICT projects, however some of the interviewees were not sure if the selection process and the project group composition always were optimal. The following comment from an engineer exemplifies this: "something we often experience, especially when we actively look for it, is the stereotype engineers. If they are grouped together, then you will experience a very slow and monotone progress, but if you connect them with others who have a more business, commercial background, you will experience another progress, and they will often have ideas the engineers would never think of. It's more fun and gives better results." Other respondents, on the other hand, were satisfied with how the project groups are composed. The most important thing to note is that those who were satisfied with the project organization were more likely to express satisfaction with not only the system implemented, but also with the organizations ICTs in general. This underlines the importance of organizing the projects properly as the Information System (IS) Success Model by Delone and McLean (2003) emphasizes that user satisfaction is an important factor in IS success.

Furthermore, participants who expressed satisfaction with the ICSs also reported that they have confidence in the ICT management. The following about the ICT management stated by an employee expresses this: "I don't know exactly what they do and what their strategies are, but I have great respect for the work they do. I'm sure they have a lot of good ideas and thought. I'm convinced of that." Similar expressions were made by several other respondents. I interpret the results to provide support for stating that user participation and user satisfaction are factors that strongly contribute to UMA.

\section{Process more important than time}

The ICT projects are very process focused from start to end and they strive to have a good process without focusing on the time it takes. The CIO gave two reasons for why they have this pol- 
icy. First, the time they invest in conducting good processes, they get back when the system is implemented. Users will be more satisfied and also use the system better and more than they would if the process was rushed. Second, he believed they are able to choose the best system for their organization by spending a lot of time and resources on the specification of requirements and finding the right supplier processes. The process focus was also evident with the other respondents, and most of them were satisfied with how the ICT project processes are conducted. One of the respondents state: "I feel it's a very good process. We who are going to use the system really decide what we want." As long as they feel their voice is heard the respondents report satisfaction with the process and acceptance of the ICT. They also express confidence to ICT management and hence UMA is strengthened.

The success factors identified as important for UMA are presented in Table 1. The factors are ranked and a comment on to which degree the studied corporation has succeeded in it is added.

Table 1 - Success factors for User Management Alignment

\begin{tabular}{|l|l|l|}
\hline \multicolumn{1}{|c|}{ Rank } & \multicolumn{1}{|c|}{ Factor } & \multicolumn{1}{c|}{ Comment } \\
\hline 1 & User participation & $\begin{array}{l}\text { Very well implemented in the organization. Can im- } \\
\text { prove in selecting the right people for the projects } \\
\text { group, and also broaden user participation in the ICT } \\
\text { strategy development process. }\end{array}$ \\
\hline 2 & Management commitment & $\begin{array}{l}\text { ICT management has high commitment, but non-ICT } \\
\text { management varies a lot. Some managers totally ig- } \\
\text { nore ICT issues, while others take them seriously. } \\
\text { Room for improvement. }\end{array}$ \\
\hline 3 & User satisfaction & $\begin{array}{l}\text { Most respondents were relatively satisfied with the } \\
\text { ICT situation. }\end{array}$ \\
\hline 4 & Project process focus & $\begin{array}{l}\text { Very well implemented. Both the CIO and the other } \\
\text { respondents consider this to be important for success. }\end{array}$ \\
\hline 5 & User initiatives & $\begin{array}{l}\text { Many of the projects, both active and completed ones, } \\
\text { have been initiated by users. A management challenge } \\
\text { is to allow the good initiatives and turn down the bad } \\
\text { ones. }\end{array}$ \\
\hline
\end{tabular}

\section{Emerging model}

From the study's findings it is possible to provide a preliminary model of User Management Alignment as shown in Figure 1. The model is based on findings in this study. User participation, user satisfaction, user initiatives, project process focus and management commitment all influence on UMA. In addition to the direct relationship between user participation and UMA, user participation also influences user satisfaction. Management commitment has an influence on user initiatives, user satisfaction and project process focus. The outcome of the UMA Model (UMAM) is improved strategy and project processes, and possibly some positive effects on UCT use. The latter relationship is modeled as reciprocal and with stippled lines as the support for it is limited in the data. 


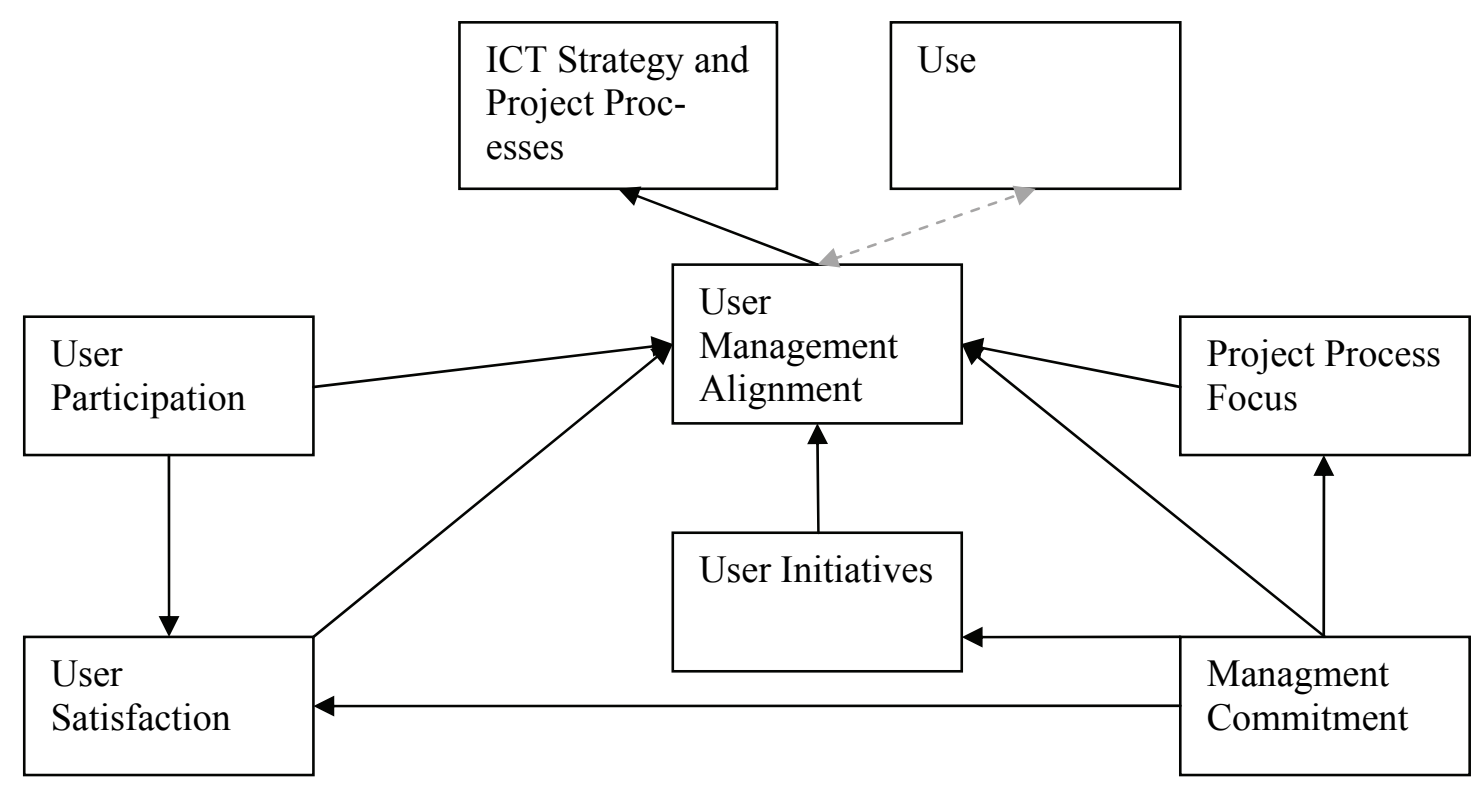

Figure 1 - the emerging User Management Alignment Model (UMAM)

\section{Limitations and Conclusion}

This study provide new insight in the knowledge sphere of ICTs in organizations and the processes involved in ICT strategy development and the conduction of ICT projects. However, there are some limitations and in the following I will discuss those and also draw the direction for future research on the subject.

When conducting single case research one should be careful to generalize the findings (Eisenhardt, 1989; Lee, 1989), which means that findings are only valid for the organization studied. However, this does not exclude the possibility that the UMAM can be applied in other domains, and it is the author's belief that it can, although the research at this stage must be characterized as explorative. The study shows that the value of the ICT user should not be underestimated, in the process of developing ICT strategies and in ICT projects. Users may very well be the initiators of projects as they possess firsthand knowledge of their needs. Concerning the overall ICT strategy that should be initiated and controlled by the ICT management, but user participation should be strong.

I will draw two main directions for future research on User Management Alignment. First of all, more cases should be studied using the same methodological approach as in this study. This would make it possible to improve the model to fit to the findings of several cases, and hence improve its generalizability. Second, future studies may operationalize and test the model. Given that these directions are followed, the author believes that the proposed model will have normative implications for practitioners as well as for future research.

\section{References}

Adams, D. A., Nelson, R. R., \& Todd, P. A. (1992). Perceived usefulness, ease of use, and usage of information technology - A replication. MIS Quarterly, 16(2), 227-247.

Agarwal, R., \& Karahanna, E. (2000). Time flies when you're having fun: Cognitive absorption and beliefs about information technology usage. MIS Quarterly, 24(4), 665-694.

Agarwal, R., \& Prasad, J. (1998). The antecedents and consequents of user perceptions in information technology adoption. Decision Support Systems, 22(1), 15-29. 
Aladwani, A. M. (2002). An integrated performance model of information systems projects. Journal of Management Information Systems, 19(1), 185-210.

Ba, S. L., Stallaert, J., \& Whinston, A. B. (2001). Research commentary: Introducing a third dimension in information systems design the case for incentive alignment. Information Systems Research, 12(3), 225-239.

Barki, H., \& Hartwick, J. (1989). Rethinking the concept of user involvement. MIS Quarterly, 13(1), 53-63.

Barki, H., \& Hartwick, J. (1994). Measuring user participation, user involvement and user attitude. MIS Quarterly, 18(1), 59-82.

Barney, J. B. (2002). Gaining and sustaining competitive advantage (Second ed.). Prentice Hall.

Broadbent, M., \& Weill, P. (1993). Improving business and information strategy alignment - Learning from the banking industry. IBM Systems Journal, 32(1), 162-179.

Brod, C. (1982). Managing technostress: Optimising the use of computer technology. Personnel Journal, 61(10), 753-757.

Carlson, P. J., \& Davis, G. B. (1998). An investigation of media selection among directors and managers: From "self" to "other" orientation. MIS Quarterly, 22(3), 335-362.

Croteau, A. M., \& Bergeron, F. (2001). An information technology trilogy: Business strategy, technological deployment and organizational performance. Journal of Strategic Information Systems, 10(2), 77-99.

Cutcliffe, J. R. (2000). Methodological issues in grounded theory. Journal of Advanced Nursing, 31(6), 1476-1484.

Davis, S., \& Wiedenbeck, S. (2001). The mediating effects of intrinsic motivation, ease of use and usefulness perceptions on performance in first-time and subsequent computer users. Interacting With Computers, 13(5), 549-580.

DeLone, W. H., \& McLean, E. R. (2003). The DeLone and McLean model of information systems success: a ten-year update. Journal of Management Information Systems, 19(4), 9-30.

Eisenhardt, K. M. (1989). Building theories from case-study research. Academy of Management Review, 14(4), 532-550.

Glaser, B. (1992). Emergence vs. forcing: Basics of grounded theory analysis. MillValley: Sociology Press.

Glaser, B. (1998). Doing grounded theory. Issues and discussions. Mill Valley, Ca: Sociology Press.

Glaser, B., \& Strauss, A. (1967). Discovery of grounded theory. strategies for qualitative research. Sociology Press.

Gottschalk, P. (2002). IT-strategi: Fagbokforlaget.

Grover, V., \& Malhotra, M. K. (1999). A framework for examining the interface between operations and information systems: Implications for research in the new millennium. Decision Sciences, 30(4), 901920.

Henderson, J. C., \& Venkatraman, N. (1993). Strategic alignment - Leveraging information technology for transforming organizations. IBM Systems Journal, 32(1), 4-16.

Henderson, J. C., \& Venkatraman, N. (1999). Strategic alignment: Leveraging information technology for transforming organizations. IBM Systems Journal, 38(2-3), 472-484.

Hunton, J. E., \& Beeler, J. D. (1997). Effects of user participation in systems development: A longitudinal field experiment. MIS Quarterly, 21(4), 359-388.

Karahanna, E., Straub, D., \& Chervany, N. (1999). Information technology adoption across time: A crosssectional comparison of pre-adoption and post-adoption beliefs. MIS Quarterly, 23(2), 183-213.

Lee, A. S. (1989). A scientific methodology for MIS case studies. MIS Quarterly, 13(1), 33-50. 
Levina, N., \& Ross, J. W. (2003). From the vendor's perspective: Exploring the value proposition in information technology outsourcing. MIS Quarterly, 27(3), 331-364.

Liaw, S.-S. (2002). Understanding user perceptions of World-wide web environments. J Comp Assist Learn, 18(2), 137-148.

Locke, K. (2001). Grounded Theory in Management Research. SAGE.

Mintzberg, H., \& Mchugh, A. (1985). Strategy formation in an adhocracy. Administrative Science Quarterly, 30(2), 160-197.

Orlikowski, W. J. (1993). Case tools as organizational change - Investigating incremental and radical changes in systems-development. MIS Quarterly, 17(3), 309-340.

Oz, E., \& Sosik, J. J. (2000). Why information systems projects are abandoned: A leadership and communication theory and exploratory study. Journal of Computer Information Systems, 41(1), 66-78.

Patton, M. Q. (1990). Qualitative evaluation and research methods (2nd ed.). London: Sage Publications.

Peak, D., Guynes, C. S., \& Kroon, V. (2005). Information technology alignment planning - A case study. Information \& Management, 42(5), 635-649.

Reich, B. H., \& Benbasat, I. (2000). Factors that influence the social dimension of alignment between business and information technology objectives. MIS Quarterly, 24(1), 81-113.

Resnik Mellion, L., \& Moran Tovin, M. (2002). Grounded theory: A qualitative research methodology for physical therapy. Physiotherapy Theory \& Practice, 18(3), 109-120.

Sabherwal, R., \& Chan, Y. E. (2001). Alignment between business and IS strategies: A study of prospectors, analyzers, and defenders. Information Systems Research, 12(1), 11-33.

Sambamurthy, V., \& Zmud, R. W. (1992). Managing IT for success: The empowering business partnership. Morristown, NJ: Financial Executives Research Foundation.

Spradley, J. P. (1979). The ethnographic interview. Forth Worth, TX: Jovanovich College Publishers.

Steinfield, C. W., \& Fulk, J. (1990). The theory imperative. Newbury Park: Sage.

Strauss, A., \& Corbin, J. (1990). Basics of qualitative research: Newbury Park: Sage Publications.

Strauss, A., \& Corbin, J. (1994). Grounded theory methodology: An overview. In I. Denzin \& N.K and Lincoln Y. S. (Eds.), Handbook of qualitative research. London: Sage.

Sørnes, J.-O. (2004). Information and communication technologies in practice A study of advanced users in the workplace in Norway and the United States. Doctoral Thesis for the degree of $\mathrm{PhD}$.

van den Hoonaard, W. C. (1997). Working with sensitizing concepts: Analytical Field Research. Newbury Park, CA: SAGE.

Venkatesh, V. (2000). Determinants of perceived ease of use: Integrating control, intrinsic motivation, and emotion into the technology acceptance model. Information Systems Research, 11(4), 342-365.

\section{Biography}

Harald Fardal is a Ph.D. student at Bodø Graduate School of Business, Norway. His research focuses on the processes involved in ICT strategy development and in ICT projects, and especially on how the competence of ICT users can strengthen these processes. Fardal also holds an Assistant Professor position at Vestfold University College, where he teaches courses in ICTmanagement. He holds a M.Sc. in information systems from Buskerud University College, Norway. 